\title{
Transcatheter pulmonary valve replacement: an option for some but not for all
}

\author{
Chirag Bavishi $^{1,2}$, Paul C. Gordon ${ }^{1,2}$, Frank W. Sellke ${ }^{1,2}$ \\ ${ }^{1}$ Lifespan Cardiovascular Institute, Rhode Island Hospital, Providence, RI, USA; ${ }^{2}$ Warren Alpert Medical School, Brown University, Providence, RI, \\ USA \\ Correspondence to: Frank W. Sellke, MD. Chief of Cardiothoracic Surgery, Karl Karlson and Gloria Karlson Professor of Cardiothoracic Surgery, \\ Rhode Island and The Miriam Hospitals, The Warren Alpert Medical School, Brown University, MOC 360, 2 Dudley St., Providence, RI 02903, \\ USA. Email: frank_sellke@brown.edu. \\ Comment on: Zhou Y, Xiong T, Bai P, et al. Clinical outcomes of transcatheter versus surgical pulmonary valve replacement: a meta-analysis. J Thorac \\ Dis 2019;11:5343-51.
}

Submitted Apr 08, 2020. Accepted for publication Apr 22, 2020.

doi: $10.21037 /$ jtd-20-1621

View this article at: http://dx.doi.org/10.21037/jtd-20-1621

Transcatheter pulmonary valve replacement (TPVR) provides a less invasive alternative to surgical pulmonary valve replacement (SPVR) in children and adults for the management of dysfunctional right ventricular outflow tract (RVOT). The most common applications of TPVR are bioprosthetic pulmonary valve dysfunction, right ventricle to pulmonary artery conduit failure or native RVOT obstruction or severe pulmonary regurgitation in patients with congenital heart disease particularly Tetralogy of Fallot (1). Currently, in the United States, the Melody ${ }^{\mathrm{TM}}$ Transcatheter Pulmonary valve (Medtronic Inc., Minneapolis, MN, USA) and Edwards Sapien (Edwards Lifesciences, Irvine, CA, USA) valve are approved for TPVR (Figure 1). The Melody valve is a trileaflet bovine jugular venous valve that is sutured onto a platinum-iridium stent. The valve is available in $16-$ and $18-\mathrm{mm}$ size for deployment up to 20 and $22 \mathrm{~mm}$ respectively. The balloon delivery system has a $22 \mathrm{~F}$ catheter diameter that can be delivered through the femoral or jugular vein. In 2016, the FDA approved Edwards Sapien XT for TPVR, which is now replaced with the newer generation Sapien S3 valve. The Sapien S3 is a trileaflet valve made of bovine pericardial tissue mounted on a cobalt chromium stent. The stent frame has a polyethylene terephthalate fabric skirt around the base. The valve comes in four sizes-20, 23, 26 and $29 \mathrm{~mm}$ and is compatible with 14 or $16 \mathrm{~F}$ expandable sheath. The Sapien S3 valve awaits the US FDA approval for use in the pulmonary position, however it's off-label use has shown promising results (3).

Zhou et al. (4) performed a meta-analysis to study the efficacy and safety of TPVR compared to SPVR. The authors included 11 observational studies with mean/median age of patients ranging from 12 to 32 years. Compared to SPVR, TPVR was associated with significant reduction in risk for all-cause mortality at the longest available follow-up (pooled odds ratio $0.43, \mathrm{P}=0.02$ ), recurrent pulmonary regurgitation (pooled odds ratio $0.17, \mathrm{P}=0.001$ ) and 30-day hospitalization (pooled odds ratio $0.67, \mathrm{P}=0.01$ ) while the risk for postprocedural infective endocarditis was significantly higher (pooled odds ratio 4.56, $\mathrm{P}<0.0002$ ). The risk for re-operation was numerically lower with SPVR compared to TPVR. The heterogeneity was largely low except for the endpoints of hospital stay and re-operation. The quality of studies was fair to good and no publication bias was seen for end-point of allcause mortality.

There are no randomized controlled trials evaluating the comparative effectiveness of TPVR and SPVR. The results of this meta-analysis showing beneficial results for TPVR is encouraging, however it should be interpreted with caution. All the included articles are retrospective cohort studies with confounding and selection bias. In addition, there is high heterogeneity in design of these studies, and there is also marked differences in the patient cohorts. For instance, the study by Alassas et al. (5) includes exclusively patients with failed pulmonary homograft with prior Ross procedure, while the study by Daily et al. included 

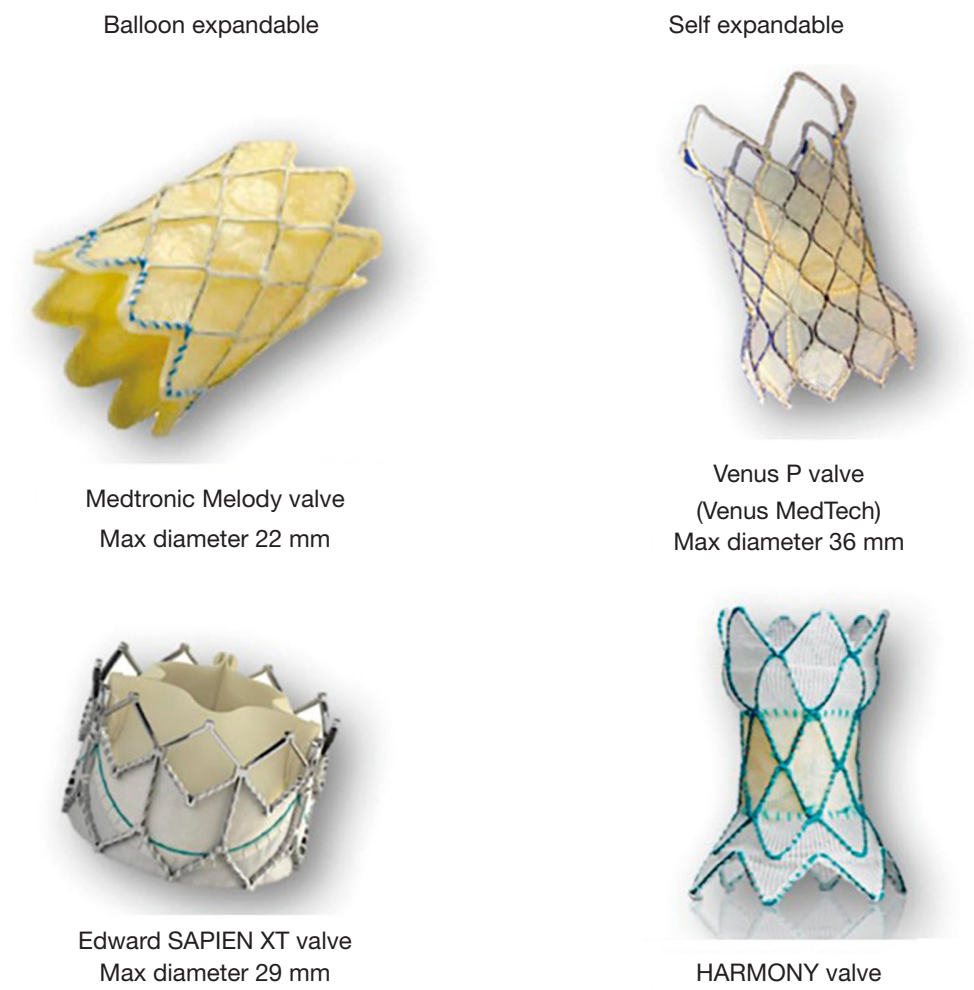

Figure 1 Various valves for TPVR. Of note, the FDA approved Edwards Sapien XT for TPVR, which is now replaced with the newer generation Sapien S3 valve which is used off-label and awaiting FDA approval for the pulmonary position [image with permission: reference (2)]. TPVR, transcatheter pulmonary valve replacement.

only patients with repaired Tetralogy of Fallot. Third, notwithstanding the small sample size of studies, 8 of the 11 studies has zero events in either of their groups. Low event rates not only undermine the power of the study but also affects the analytic consistency. Methods based on Poisson regression with random effects may help to mitigate part of this limitation.

Advances in surgical interventions and peri-operative care for congenital heart diseases has allowed increasing number of children to survive till adulthood. SPVR is one of the common operations performed in adult patients with congenital heart disease. It is associated with low mortality and morbidity. In the Society of Thoracic Surgeons Congenital Heart Surgery Database [2007-2013], patients who underwent SPVR, in-hospital mortality was $0.9 \%$ while in the Adult Cardiac Surgery Database [2007-2013], the inhospital mortality was reported as $4.1 \%$ (6). However, most of these patients will require multiple surgical procedures over the course of their lifetime. Moreover, some of these reoperations are often complex and associated with increased morbidity and mortality (7) particularly in adult patients compared to pediatric patients, likely due to a higher prevalence of other pre-operative comorbidities and risk factors. TPVR may offer a minimally invasive option for earlier treatment of a dysfunctional pulmonary bioprosthesis or conduit before the onset of irreversible right ventricular failure ensues. Pulmonary hemorrhage, stent or valve embolization, coronary artery compression and conduit tear are major intra-procedural risks while stent fracture and valve endocarditis remain a major concern post TPVR. With the increase in operators experience, the risks for these intra-procedural complications is $3-4 \%$ (8). TPVR may be challenging in patients with large RVOT or native RVOT with patch repair. However, with the increasing use of larger Sapien S3 valves, TPVR for large RVOT can be successfully performed. In the study by Sinha et al. (3) on off-label experience of using Sapien S3 valve in 50 TPVR cases, 38 Sapien S3 were placed into native RVOTs with 24 to $32 \mathrm{~mm}$ diameter. There were no intraprocedural deaths however tricuspid valve injury with the 
delivery catheter was seen in 6\% cases. Recently, Edwards Lifesciences introduced the Alterra Adaptive Prestent which comprises a nitinol framed radiopaque self-expanding, stent with a polyethylene terephthalate fabric covering to provide a suitable landing zone for the Sapien S3 $29 \mathrm{~mm}$ valve for large RVOT diameters (9).

Trials are currently underway to study novel devices that, if approved, will expand the availability of TPVR to an even broader population of patients with neo RVOT dysfunction. Early feasibility studies in humans involving Medtronic Harmony TPV (Medtronic, Inc.) (10), Venus $\mathrm{P}$ valve (Venus MedTech, Shanghai, China) (11), and the Pulsta valve (TaeWoong Medical Co, Gimpo, Korea) (12) have shown promising results. However, larger studies with longer follow-up are needed to confirm these preliminary observations and safety of these devices. Hybrid approaches involving both surgeons and interventionalist have also been described and can overcome some of the limitations of percutaneous approaches (2).

SPVR still remains the gold standard for patients with congenital heart diseases. TPVR can be a reliable and safe alternative to SPVR in patients that have undergone prior surgeries for congenital heart disease. A careful anatomic and hemodynamic assessment is essential to select appropriate candidates for this procedure.

\section{Acknowledgments}

Funding: None.

\section{Footnote}

Provenance and Peer Review: This article was commissioned by the editorial office, Fournal of Thoracic Disease. The article did not undergo external peer review.

Conflicts of Interest: All authors have completed the ICMJE uniform disclosure form (available at http://dx.doi. org/10.21037/jtd-20-1621). The authors have no conflicts of interest to declare.

Ethical Statement: The authors are accountable for all aspects of the work in ensuring that questions related to the accuracy or integrity of any part of the work are appropriately investigated and resolved.

Open Access Statement: This is an Open Access article distributed in accordance with the Creative Commons
Attribution-NonCommercial-NoDerivs 4.0 International License (CC BY-NC-ND 4.0), which permits the noncommercial replication and distribution of the article with the strict proviso that no changes or edits are made and the original work is properly cited (including links to both the formal publication through the relevant DOI and the license). See: https://creativecommons.org/licenses/by-nc-nd/4.0/.

\section{References}

1. Stout KK, Daniels CJ, Aboulhosn JA, et al. 2018 AHA/ ACC Guideline for the Management of Adults With Congenital Heart Disease: Executive Summary: A Report of the American College of Cardiology/American Heart Association Task Force on Clinical Practice Guidelines. Circulation 2019;139:e637-97.

2. Kim SH. Recent advances in pediatric interventional cardiology. Korean J Pediatr 2017;60:237-44.

3. Sinha S, Aboulhosn J, Asnes J, et al. Initial results from the off-label use of the SAPIEN S3 valve for percutaneous transcatheter pulmonary valve replacement: A multiinstitutional experience. Catheter Cardiovasc Interv 2019;93:455-63.

4. Zhou Y, Xiong T, Bai P, et al. Clinical outcomes of transcatheter versus surgical pulmonary valve replacement: a meta-analysis. J Thorac Dis 2019;11:5343-51.

5. Alassas K, Mohty D, Clavel MA, et al. Transcatheter versus surgical valve replacement for a failed pulmonary homograft in the Ross population. J Thorac Cardiovasc Surg 2018;155:1434-44.

6. Khanna AD, Hill KD, Pasquali SK, et al. Benchmark Outcomes for Pulmonary Valve Replacement Using The Society of Thoracic Surgeons Databases. Ann Thorac Surg 2015;100:138-45; discussion 145-6.

7. Oechslin EN, Harrison DA, Harris L, et al. Reoperation in adults with repair of tetralogy of fallot: indications and outcomes. J Thorac Cardiovasc Surg 1999;118:245-51.

8. Chatterjee A, Bajaj NS, McMahon WS, et al.

Transcatheter Pulmonary Valve Implantation: A Comprehensive Systematic Review and Meta-Analyses of Observational Studies. J Am Heart Assoc 2017. doi: 10.1161/JAHA.117.006432.

9. Zahn EM, Chang JC, Armer D, et al. First human implant of the Alterra Adaptive PrestentTM: A new self-expanding device designed to remodel the right ventricular outflow tract. Catheter Cardiovasc Interv 2018;91:1125-9.

10. Schoonbeek RC, Takebayashi S, Aoki C, et al. Implantation of the Medtronic Harmony Transcatheter 
Pulmonary Valve Improves Right Ventricular Size and Function in an Ovine Model of Postoperative Chronic Pulmonary Insufficiency. Circ Cardiovasc Interv 2016. doi: 10.1161/CIRCINTERVENTIONS.116.003920.

11. Garay F, Pan X, Zhang YJ, et al. Early experience with the Venus p-valve for percutaneous pulmonary valve implantation in native outflow tract. Neth Heart J

Cite this article as: Bavishi C, Gordon PC, Sellke FW. Transcatheter pulmonary valve replacement: an option for some but not for all. J Thorac Dis 2020;12(11):6422-6425. doi: 10.21037/ jtd-20-1621
2017;25:76-81.

12. Kim GB, Song MK, Bae EJ, et al. Successful Feasibility Human Trial of a New Self-Expandable Percutaneous Pulmonary Valve (Pulsta Valve) Implantation Using Knitted Nitinol Wire Backbone and Trileaflet $\alpha$-Gal-Free Porcine Pericardial Valve in the Native Right Ventricular Outflow Tract. Circ Cardiovasc Interv 2018;11:e06494. 